\title{
The Study and Identification of Bacterial Spoilage Species Isolated from Catfish during Refrigerated Storage
}

KaLonna D. MaulI ${ }^{1}$, Michael E. Hickey ${ }^{1,2}$ and Jung-Lim Lee ${ }^{1 *}$

${ }^{1}$ Department of Human Ecology, College of Agriculture and Related Sciences, Delaware State University, 1200 North DuPont Highway, Dover, DE 19901, USA

${ }^{2}$ Department of Biology, Wesley College, Dover, DE 19901, USA

\begin{abstract}
Catfish farming is relatively new in the state of Delaware although it has been a long standing profitable business in the southern United States. Catfish fillets used in this study were stored at $4^{\circ} \mathrm{C}$ for $1-2$ weeks, after which, bacterial growth was expected on the surface of the fish. Bacteria were isolated and cultured on selective and differential media. Bacterial growth curves formulated from results in this study can be used to assess the shelf-life of catfish fillets under refrigerated storage. A specific spoilage organism was targeted to further understand and prevent microbial degradation of catfish fillets. The need for target gene $16 \mathrm{~S}$ to be used for the discrimination of Pseudomonas spp. was confirmed rather than target gene rpoD; as it does not discriminate sufficiently to permit resolution of Pseudomonas spp. intrageneric relationships. Pseudomonas spp., Shewanella spp., Bacillus spp., Myroides spp., Aeromonas spp., and Enterobacter spp. were found to be contributors to the spoilage of catfish in the state of Delaware through method of 16S rDNA sequencing. The comparison of spoilage rates from both retail purchased and pond obtained catfish fillets illustrated need for increased catfish farming and production for sustainability in the State of Delaware.
\end{abstract}

Keywords: Catfish; Bacterial spoilage; Identification; Geographical origin

\section{Introduction}

Channel catfish (Ictalurus punctatus) is the most important aquaculture species in the United States accounting for more than $60 \%$ of its aquaculture production [1]. Fish is one of the most vulnerable of the world's resources as fillets deteriorate rapidly due to microbial degradation [2]. Fish quality is a complex concept that incorporates many factors for consumers such as safety, nutritional quality, availability, freshness, eating quality, and physical attributes of the species [3]. Bacterial spoilage of iced and refrigerated fishery products increases during storage time, however, the shelf life of freshly harvested fish is dependent upon factors such as bacterial flora, processing, storage temperature, and handling [3]. Commercial processing of channel catfish spread skin and gut microflora on work surface and processing equipment, which ultimately increase contamination of final retailed product [4].

Microbial spoilage can manifest itself as visible growth with slime, colonies, textural changes as polymers degrade, gapping, off-odors, or off-flavors [5]. Worldwide, microbial spoilage of food leads to considerable economic losses. It has been estimated that as much as $25 \%$ of all food produced is lost post-harvest due to microbial activity [6]. Minimizing the financial impact of food spoilage by industry requires strategies that control organisms responsible for product degradation [7]. The establishment of the "specific spoilage organism" (SSO) concept has helped fundamentally shape the understanding of seafood spoilage. Studies of many seafood products have shown that the amount of SSOs present can be used to predict the remaining shelf life of products making identification of these bacteria a top priority [6].

This study was conducted to identify bacterial spoilage species present on catfish fillets. Through the selection of unique bacterial colonies from spoiled catfish fillets, this research aimed to classify the diversified bacterial communities that aid in the spoilage of retail and pond catfish within the state of Delaware. As specific bacterial species contributing to catfish spoilage were determined, this research provides the industry and consumers with significant information towards understanding, delaying, and possibly preventing microbial degradation on fishery products. Stakeholders in the seafood business would be highly interested in keeping their investment of fish safe through processing in order to see their anticipated profit. This investigation also offers insight into the shelf-life of fish during refrigerated storage and could be useful for manufacturers looking to optimize processing and shipping techniques without compromising the overall quality of their product. This study distinguishes itself because it is the first known attempt to isolate spoilage bacteria from catfish in the state of Delaware. The accurate characterization of bacteria attributed to spoilage in this area is extremely beneficial to the state and surrounding catfish farmers. All data was cross referenced with results from tests performed on selective and differential agar, Polymerase Chain Reaction (PCR) screening, 16S rDNA sequencing, and phylogenetic tree construction. Results can be compared with other states or regions and effective precautions to inhibit bacterial growth could be implemented. The accurate identification of spoilage bacteria affecting catfish in the mid-Atlantic region increases awareness and encourages further testing of microbial degradation in this industry. This research served as a foundation for more detailed studies into fish spoilage mechanisms. In determining which species of bacteria contribute to fish spoilage, a better chance of reversing their adverse effects is possible. Issues such as food safety, seafood contamination, and post-harvest preservation remain a concern in the food industry.

*Corresponding author: Jung-Lim Lee, Department of Human Ecology, Delaware State University, 1200 North DuPont Highway, Dover, DE, 19901, USA, Tel: 302 857-6448; E-mail: jlee@desu.edu

Received September 18, 2012; Accepted November 09, 2012; Published November 17, 2012

Citation: Maull KD, Hickey ME, Lee JI (2012) The Study and Identification of Bacterial Spoilage Species Isolated from Catfish during Refrigerated Storage. J Food Process Technol S11-003. doi:10.4172/2157-7110.S11-003

Copyright: @ 2012 Maull KD, et al. This is an open-access article distributed unde the terms of the Creative Commons Attribution License, which permits unrestricted use, distribution, and reproduction in any medium, provided the original author and source are credited. 
Identifying specific spoilage organisms indicative of this region allow for the comparison of other identified species that have been unknown contributors to seafood spoilage.

\section{Materials and Methods}

\section{Fish sample}

The fish used in this research was North Atlantic channel catfish. Catfish samples from a local retail source in Dover, Delaware were acquired from an official U.S. farm-raised catfish processor in North Carolina. The Aquaculture Research and Demonstration Facility Earthen Aquaculture Ponds at Delaware State University also provided channel catfish to this study. All catfish fillets were purchased and used for sampling from early spring to summer. Sampling of retail source fillets began on March 16, 2011 and ended in May 16, 2011. Sampling of pond source fillets began on May 26, 2011 and ended in July 22, 2011. The fish were filleted by experienced staff and samples were packed in bags, kept on ice, and immediately transported to the food microbiology laboratory. Samples were stored at $4^{\circ} \mathrm{C}$ for 2-3 weeks depending on fillet spoilage. Half of each fillet was used for a sensory evaluation; the other half was divided into $10 \mathrm{~g}$ portions and put into stomacher bags (Stomacher 3500, Seward Inc., Bohemia, New York, USA).

\section{Bacterial isolation}

Bacteria were isolated every two days using $10 \mathrm{~g}$ catfish sample was homogenized with $50 \mathrm{ml}$ of saline solution. Tenfold dilution were performed using $100 \mu \mathrm{l}$ of pure sample into $900 \mu \mathrm{l}$ of Tryptic Soy Broth (TSB) (Carolina, Burlington, North Carolina, USA) plated onto Tryptic Soy Agar (TSA) (Carolina, Burlington, North Carolina, USA) and Pseudomonas Isolation Agar (Difco ${ }^{\mathrm{ma}}$, Sparks, Maryland, USA). Isolated cultures were incubated at $25^{\circ} \mathrm{C}$ for 3 days and bacteria colonies (CFU) were enumerated. Catfish fillets reached a spoiled state after 12 to 18 days and the cycle was repeated using fresh catfish fillets. Candidate colonies of unknown spp. were collected at each sampling. Isolates were plated on Pseudomonas Putida Agar and Pseudomonas Fluorescens Agar (Difco, Sparks, Maryland, USA) for further identification.

\section{DNA extraction}

DNA extraction was performed using $100 \mu \mathrm{l}$ of stored glycerol stock sample into $10 \mathrm{ml}$ of TSB. Once turbid, $1 \mathrm{ml}$ of inoculated TSB was transferred to a $2 \mathrm{ml}$ microcentrifuge tube, centrifuged at 14,000 $\mathrm{xg}$ for 4 minutes at $14^{\circ} \mathrm{C}$ and supernatant was discarded. Pellet was re-suspended in $200 \mu \mathrm{l}$ of molecular grade water and put into a $100^{\circ} \mathrm{C}$ water bath for $10 \mathrm{~min}$. Tube was centrifuged at $14,000 \mathrm{xg}$ for $4 \mathrm{~min}$ at $14^{\circ} \mathrm{C}$. Fifty $\mu$ l of DNA template containing supernatant was transferred to a new micro centrifuge tube and used for PCR assay.

\section{PCR for detection of Pseudomonas spp.}

Each PCR tube contained: $2 \mu \mathrm{l}$ of extracted DNA template, $10 \mu \mathrm{l}$ of PCR water, $1 \mu \mathrm{l}$ of forward primer, $1 \mu \mathrm{l}$ of reverse primer, and $15 \mu \mathrm{l}$ of 2x Taq (New England BioLabs Inc. OneTaq, Ipswich, Massachusetts, USA). PCR was performed using the following parameters: initial DNA denaturation at $95^{\circ} \mathrm{C}$ for $4 \mathrm{~min}, 34$ cycles of DNA denaturation at $95^{\circ} \mathrm{C}$ for $35 \mathrm{sec}$, annealing at $54^{\circ} \mathrm{C}$ for $30 \mathrm{sec}$, extension at $72^{\circ} \mathrm{C}$ for $50 \mathrm{sec}$, and final extension of DNA at $72^{\circ} \mathrm{C}$ for $4 \mathrm{~min}$. Primers used to identify Pseudomonas spp. were $1 \mu \mathrm{mol}$ universal Pseudomonas primers PSEG30F and PSEG79R consisting of sequences 5'-ATYGAA-ATC-GCC-AAR-CG-3' and 5'-CGG-TTG-ATK-TCC-TTG-A3'(Sigma Genosys, Woodlands, Texas, USA) that targeted the rpo D gene of DNA.

\section{Gel electrophoresis}

PCR amplicons positive for Pseudomonas spp. were run on 82 $\mathrm{V}$ agarose gel electrophoresis for $30 \mathrm{~min}$ and stained with ethidium bromide (Amresco $0.625 \mathrm{mg} / \mathrm{mL}$, Solon, Ohio, United States). A 1\% agarose (Amresco Agarose I, Solon, Ohio, United States) gel in 0.5X Tris-Acetate-EDTA (TAE) buffer was used for separating PCR products. Bands were photographed (Syngene G: Box, Frederick, Maryland, United States) for visual analysis, sample comparison, and separation.

\section{DNA sequencing}

Twenty candidate bacterial isolates were DNA sequenced based on unique colony morphologies. One-hundred $\mu \mathrm{l}$ of each isolate was inoculated into $10 \mathrm{ml}$ of TSB for overnight incubation. Each candidate was streaked onto TSA and incubated at $28^{\circ} \mathrm{C}$ to obtain pure culture for GENEWIZ analysis. 16S rDNA sequencing was performed by GENEWIZ, Inc (South Plainfield, NJ, USA).

\section{Phylogenetic tree reconstruction}

Isolates $16 \mathrm{~S}$ rDNA sequencing data was used to identify bacterial species using Nucleotide BLAST in Genbank database (www.ncbi. nlm.nih.gov/genbank/). Identity was chosen based on $99 \%$ or greater matches. Strain sequences were acquired through access to List of Prokaryotic Names with Standing in Nomenclature (LPSN) (www. bacterio.cict.fr/). Multiple gene alignments were performed using the software program Clauster W [8]. Phylogenetic tree was constructed by the neighbor-joining method using the software MEGA4 [8]. This data was compared to a known strain and bootstrap values were computed.

\section{Results}

\section{Bacterial enumeration}

Plating on Pseudomonas Isolation agar showed a log reduction of 2 when the initial spoilage of retail fillets were compared to initial spoilage of pond fillets. Plating on TSA, showed a 1.6 log reduction of initial spoilage of retail fillets compared to initial spoilage of pond fillets. Final spoilage rates calculated during the stationary phase of both retail and pond fillets showed that pond fillets have less bacteria present with $1 \log$ reduction shown on selective media and $1.2 \log$ reduction shown on rich media. Therefore, it was confirmed that fillets obtained from the local retail source would have higher spoilage rates than those fillets obtained from the pond source. Change in bacterial growth was likely due to the significant spoilage that took place prior to retail fillets reaching their final destination for sale. This data proves the importance of understanding a products dependency on variations in the storage conditions [9].

\section{Bacterial isolation}

Total of 237 bacterial colonies were isolated after six isolation trials. Based on colony morphology, the majority of isolated colonies maintained a circular shape. Colonies frequently appeared yellow, orange, white, or translucent in color with slight elevation. As indicated by Gram and Huss [10] in a related study, Pseudomonas spp. and Shewanella spp. presence were expected on fresh catfish fillets. Fillets obtained from retail sources reached a spoilage state much faster than fillets obtained from pond source (Figure 1).

\section{DNA extraction, PCR, and gel electrophoresis}

Agar plate, PCR screening, and gel electrophoresis results showed that bacterial colonies isolated from retail catfish had higher percentages 

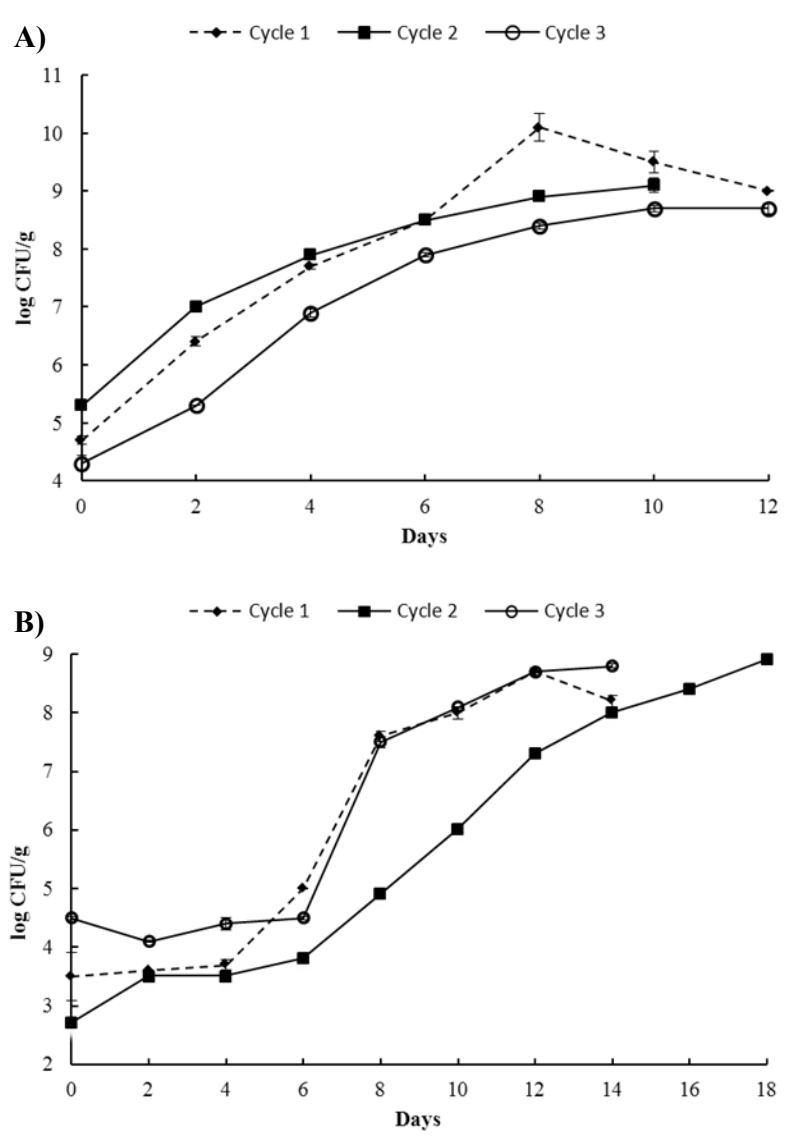

Figure 1: Increase of $\log \mathrm{CFU} / \mathrm{g}$ on a catfish fillets stored at $4^{\circ} \mathrm{C}$. (A) Spoilage rates of catfish fillets purchased from a retail source on TSA for cycles 1, 2, and 3. (B) Spoilage rates of catfish fillets from the Aquaculture Research and Demonstration Facility Earthen Aquaculture Ponds at Delaware State University on TSA for cycles 1,2 , and 3 .

Pseudomonas spp. than those of the pond sources. Thirty percent of retail fillets tested positive for Pseudomonas fluorescens using agar plating method while $24 \%$ of pond fillets tested positive. Fifty-three percent of samples from retail fillets screened positive for Pseudomonas spp. through PCR assay and gel electrophoresis while $42 \%$ of pond fillet samples showed positive test results. No positive results for agar plate tests on Pseudomonas putida were obtained which remained consistent in both retail and pond samples.

\section{$16 \mathrm{~S}$ rDNA gene analysis}

Samples 1, 4, 5, 9, 10, 11, 13, 14 and 15 were all identified as Pseudomonas spp. (Table 1). Sample 1 showed 100\% match to Pseudomonas reactans, Pseudomonas grimontii, and Pseudomonas fluorescens. These results compared to other samples with just one match at $100 \%$ accuracy raised concern. Results obtained by Mulet et al. [11] showed the $16 \mathrm{~S}$ rDNA gene sequence is a good tool for phylogenetic studies, however, in many cases it does not discriminate sufficiently to permit resolution of Pseudomonas spp. intrageneric relationships because of its slow rate of evolution. The matching of Pseudomonas spp. resulted in a single sample obtained from the $16 \mathrm{~S}$ rDNA sequencing results found in table 1 support these findings (Figure 2) [11].

Consistency between data received from gene alignment and phylogenetic tree analysis was maintained in most samples. Only 2 of 20 isolates showed variation; likely due to the contrast in protocol between gene alignment findings and phylogenetic tree data. Sequences were matched using 700-1000 bp sequences. In phylogenetic tree reconstruction, a larger range of base pairs usually greater than 1400 are recommended. This explains why sample 14 and 20 were not directly joined to a standard strain as shown in figure 3 . Twenty unique isolates from both retail and pond sources were combined into 1 phylogenetic tree. Pseudomonas spp., Shewanella spp., Bacillus spp., Myroides spp., Aeromonas spp., and Enterobacter spp. were all represented (Figure 3).

\section{Discussion}

Data confirmed that catfish fillets acquired directly from pond source have significantly lower bacterial growth rates despite being obtained during the summer months with higher anticipated bacterial activity than those obtained from the retail sources. Bacterial spoilage on iced and refrigerated fishery products is dependent upon many factors including processing, storage, and handling [3]. The process of moving catfish fillets to allotted retail establishments causes increased bacteria detection. Less handling, decreased transportation, and reduced storage time significantly decrease the risk of contamination.

Both Pseudomonas spp. and Shewanella spp. identification were expected during sequencing and phylogenetic analysis. Shewanella putrefaciens is the primary spoilage bacteria of marine temperate-water
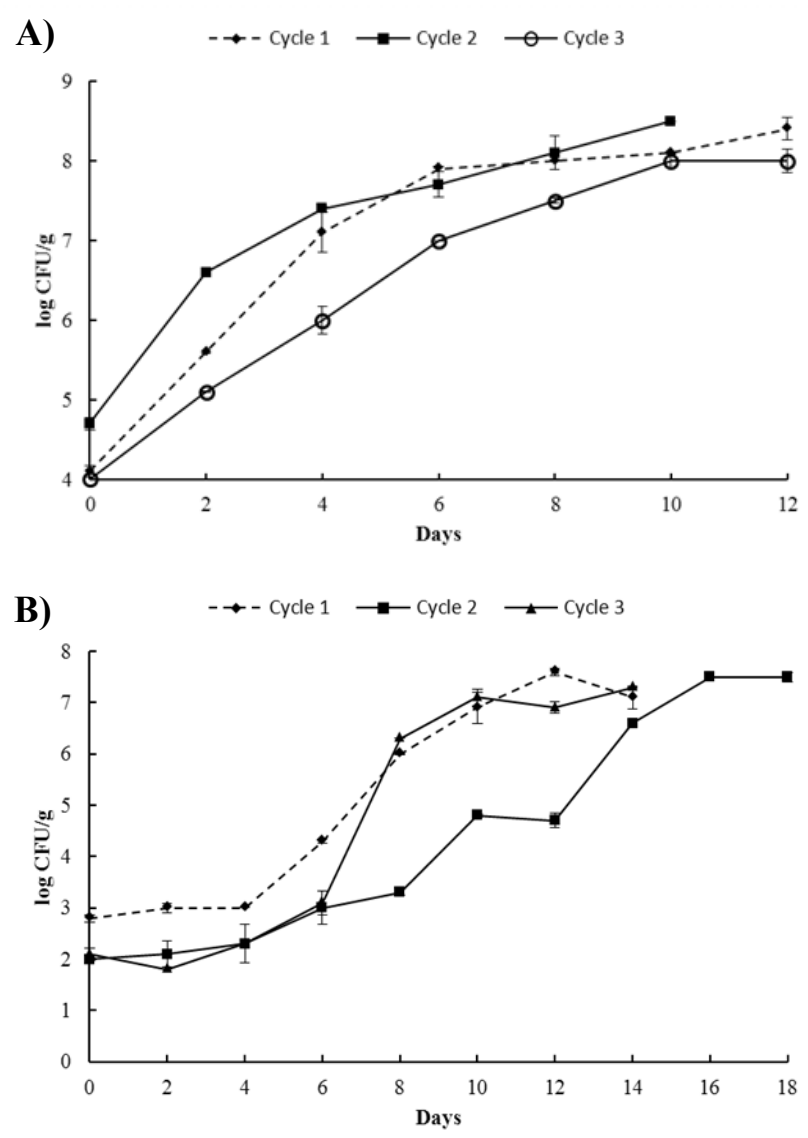

Figure 2: Increase of log CFU/g on a catfish fillets stored at $4^{\circ} \mathrm{C}$. (A) Spoilage rates of catfish fillets from a retail source when plated on Pseudomonas Isolation Agar for cycles 1, 2, and 3. (B) Spoilage rates of catfish fillets from the Aquaculture Research and Demonstration Facility Earthen Aquaculture Ponds at Delaware State University on Pseudomonas Isolation Agar. 


\begin{tabular}{|c|c|c|c|c|c|}
\hline $\begin{array}{l}\text { Catfish } \\
\text { Isolate }\end{array}$ & $\begin{array}{l}\text { Bacterial Identification } \\
16 S \text { rDNA Sequencing Result }\end{array}$ & Similarity $(\%)^{a}$ & $\begin{array}{l}\text { Length } \\
(\mathrm{bp})^{\mathrm{b}}\end{array}$ & GenBank Accession & Marine Type Origir \\
\hline \multirow[t]{3}{*}{1} & Pseudomonas reactans & 100 & 1374 & JN411452 & Fresh \\
\hline & Pseudomonas grimontii & 100 & 1382 & JQ282836 & Fresh \\
\hline & Pseudomonas fluorescens & 100 & 1319 & JN411357 & Fresh \\
\hline \multirow[t]{2}{*}{2} & Shewanella profunda & 99 & 1530 & FR733713 & Fresh \\
\hline & Shewanella putrefaciens & 99 & 1468 & AB681550 & Fresh/Brackish \\
\hline 3 & Shewanella baltica & 99 & 1481 & JF327458 & Fresh/Brackish \\
\hline 4 & Pseudomonas fragi & 99 & 1462 & AB680221 & Fresh \\
\hline \multirow[t]{3}{*}{5} & Pseudomonas reactans & 99 & 1374 & JN411452 & Fresh \\
\hline & Pseudomonas grimontii & 99 & 1382 & JQ282836 & Fresh \\
\hline & Pseudomonas fluorescens & 99 & 1319 & JN411357 & Fresh \\
\hline \multirow[t]{2}{*}{6} & Shewanella profunda & 99 & 1530 & FR733713 & Fresh \\
\hline & Shewanella putrefaciens & 100 & 1468 & AB681550 & Fresh/Brackish \\
\hline 7 & Pseudomonas fragi & 100 & 1459 & AB685609 & Fresh \\
\hline 8 & Myroides marinus & 99 & 1388 & GQ857652 & Fresh/Brackish \\
\hline \multirow[t]{2}{*}{9} & Pseudomonas auricularis & 100 & 1463 & AB681727 & Fresh \\
\hline & Pseudomonas poae & 100 & 1326 & HQ898911 & Fresh \\
\hline \multirow[t]{2}{*}{10} & Pseudomonas gessardii & 100 & 1516 & AF074384 & Fresh \\
\hline & Pseudomonas fluorescens & 100 & 1457 & JQ236807 & Fresh \\
\hline \multirow[t]{2}{*}{11} & Pseudomonas gessardii & 100 & 1516 & AF074384 & Fresh \\
\hline & Pseudomonas fluorescens & 100 & 1457 & JQ236807 & Fresh \\
\hline 12 & Bacillus aryabhattai & 100 & 1475 & JN700141 & Fresh/Brackish \\
\hline 13 & Pseudomonas veronii & 99 & 1459 & AB494445 & Fresh \\
\hline 14 & Pseudomonas oryzihabitans & 100 & 1463 & AB681726 & Fresh \\
\hline 15 & Pseudomonas marginalis & 100 & 1489 & HE586396 & Fresh \\
\hline 16 & Rahnella aquatilis & 99 & 1432 & JN712163 & Fresh \\
\hline 17 & Aeromonas veronii & 99 & 1458 & JQ301791 & Fresh/Brackish \\
\hline \multirow[t]{2}{*}{18} & Bacillus thuringiensis & 100 & 904 & HE648112 & Fresh \\
\hline & Bacillus cereus & 100 & 909 & HQ873674 & Fresh/Brackish \\
\hline \multirow[t]{2}{*}{19} & Bacillus thuringiensis & 100 & 1396 & JQ342872 & Fresh \\
\hline & Bacillus cereus & 100 & 1450 & JQ248587 & Fresh/Brackish \\
\hline \multirow[t]{2}{*}{20} & Enterobacter asburiae & 99 & 1465 & HQ242717 & Fresh/Brackish \\
\hline & Enterobacter cloacae & 99 & 1437 & HQ220157 & Fresh \\
\hline
\end{tabular}

a: Similarity of $16 \mathrm{~S}$ rDNA region between catfish isolated samples and closest relative found in GenBank database

b: base pair used for gene alignment.

Table 1: Gene Alignment of 20 Bacteria Isolated after DNA Sequencing

fish stored aerobically in ice. Pseudomonas spp. is the specific spoiler of ice stored tropical freshwater fish stored at psychotropic temperature. Shewanella putrefaciens, is another known spoiler of marine tropical fish stored on ice [9].

Bacillus spp. is ubiquitous and diverse in terrestrial and marine ecosystems and can be introduced in food during processing [12]. Bacillus includes species such as Bacillus cereus, Bacillus licheniformis, or Bacillus subtilis that may be present in fresh and pasteurized food products due to their ability to generate heat-resistant spores under adverse environmental conditions [12]. Bacillus cereus has been recognized as a causative agent of food poisoning for more than 40 years and has been linked to foodborne emetic and diarrheal syndromes [12]. Moreover, this species is known to cause spoilage in bread. Ropy spoilage of bread, for example is usually caused by Bacillus spp., especially Bacillus subtilis and Bacillus licheniformis. Other endospore formers like Bacillus pumilus and Bacillus cereus have also been isolated from spoiled bread [13]. The natural vulnerability of catfish makes such a resistant bacterial species a serious threat.

The genus Myroides was formed in 1996 in which two species are derived from a single phylogenetic branch; Myroides odoratus, formerly Flavobacteria odoratum, and Myroides odoratimimus [14]. Myroides spp. are widely distributed in water and soil particularly. Flavobacteria, previously classified under the genus Myroides, was known for its presence on fish and shellfish but their role in the spoilage of chilled fish was thought to be minor compared with that of Pseudomonas spp. [15].

Aeromonas spp. are inhabitants of a wide range of aquatic ecosystems such as freshwater, estuarine, coastal waters, and in water with levels of chlorine [16]. Foods of animal origin, including seafood, have been considered important sources of Aeromonas spp. infection [16]. Aeromonas spp., principally Aeromonas hydrophila, currently have the status of foodborne pathogen of emerging importance. It has attracted attention primarily because of its ability to grow at psychotropic temperature. Aeromonas hydrophila has been isolated from a wide range of animal and plant food products including raw meat, poultry, fin fish, seafood, dairy products, vegetables, and miscellaneous foods [17].

Food may be contaminated with Enterobacter sakazakii under conditions of hygiene mismanagement by contaminated insects and rats. Enterobacter sakazakii has been detected in food production as well as in domestic environments [18].

Based on these findings, it is important to broaden the scope of future research studies in this area. It is also essential to conduct sampling of both pond and retail fillets during the same season to decrease spoilage variables. Broadening the scope of this investigation by incorporating more retail and pond sources to sample in the area would increase the accuracy of bacterial identification in the state and Mid-Atlantic region. It would also encourage more cross-discipline collaboration and partnerships between neighboring universities.

The identification of six specific bacterial species contributing to catfish spoilage in this study now offer the industry and seafood consumers valuable data as it relates to microbial degradation on fishery products. Investors in the state of Delaware also benefit from these results as this study gives deeper insight on bacterial species that jeopardize aquaculture profits. It is the hope of the authors to highlight the necessity of more catfish farming in the state of Delaware. Benefits such as decreased spoilage and less points of contamination make implementing locally produced and harvested fish products a clear 
Citation: Maull KD, Hickey ME, Lee Jl (2012) The Study and Identification of Bacterial Spoilage Species Isolated from Catfish during Refrigerated Storage. J Food Process Technol S11-003. doi:10.4172/2157-7110.S11-003

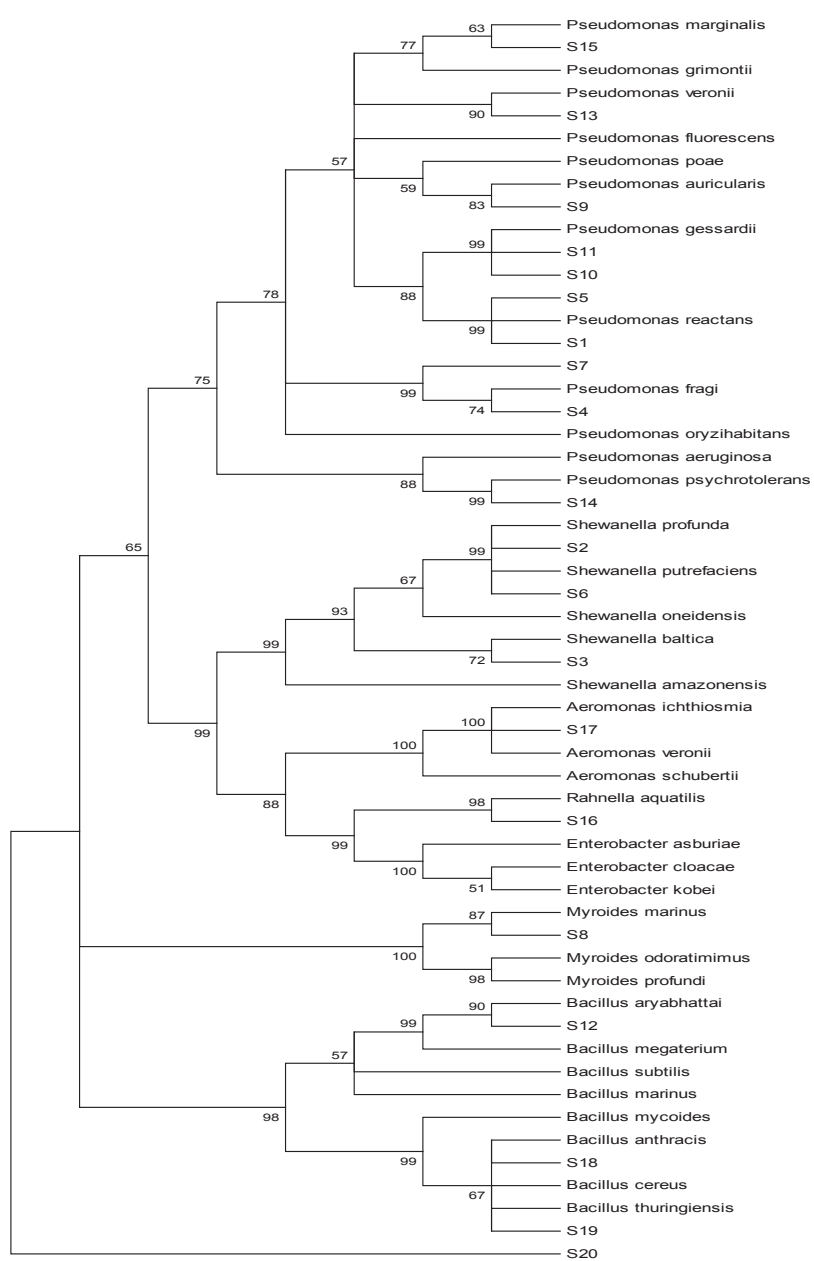

Figure 3: Phylogenetic Tree Reconstruction. Diagram shows the species identified from the 20 samples selected. Pseudomonas spp., Shewanella spp., Bacillus spp., Myroides spp., Aeromonas spp., and Enterobacter spp. were represented.

solution. In addition to more sustainable products, locally produced catfish would boost the economy and keep resources allotted for shipping in the state of Delaware.

\section{Acknowledgements}

Authors would like to acknowledge Dr. Christopher Sommers, USDA ARS ERRC, Wyndmoor, PA for his review and constructive suggestions for this manuscript as well as Dr. Dennis Mclntosh and Mr. Grant Blank of the Aquaculture Research and Demonstration Facility Earthen Aquaculture Ponds for their cooperation of this research. This study was supported by Delaware EPSCoR RII CIBER Seed grants

\section{References}

1. Liu H, Takano T, Abernathy J, Wang S, Sha Z, et al. (2010) Structure and expression of transferrin gene of channel catfish, Ictalurus punctatus. Fish \& Shellfish Immunology 28: 159-166.

2. Manju S, Jose L, Gopal TKS, Ravishankar CN, Lalitha K (2007) Effects of sodium acetate dip treatment and vacuum-packaging on chemical, microbiological, textural, and sensory changes of Pearlspot (Etroplus suratensis) during chill storage. Food Chemistry 102: 27-35.

This article was originally published in a special issue, Catfish Safety handled by Editor(s). Dr. Christopher H Sommers, EUSDA's Eastern Regional Research Center, USA
3. Abbas KA, Mohamed A, Jamilah B, Ebrahimian M (2008) A review on Correlations between Fish Freshness and $\mathrm{pH}$ during Cold Storage. American Journal of Biochemistry and Biotechnology 4: 416-421.

4. Bal'a M, Podolak R, Marshall D (2000) Microbial and color quantity of fillets obtained from steam-pasteurized deheaded and eviscerated whole catfish Food Microbiology 17: 625-631.

5. Gram L, Ravn L, Rasch M, Bruhn JB, Christensen AB, et al. (2002) Food spoilage-interactions between food spoilage bacteria. International Journal of Food Microbiology 78: 79-97.

6. Gram L, Dalgaard P (2002) Fish spoilage bacteria-problems and solutions Current Opinion in Biotechnology 13: 262-266.

7. Waite JG, Jones JM, Yousef AE (2009) Isolation and identification of spoilage microorganisms using food-based media combined with rDNA sequencing: Ranch dressing as a model food. Food Microbiology 26: 235-239.

8. Tamura K, Dudley J, Nei M, Kumar S (2007) MEGA4: Molecular Evolutionary Genetics Analysis (MEGA) Software Version 4.0. Mol Biol Evol 24: 1596-1599.

9. Rasmussen SKJ, Ross T, Olley J, McMeekin T (2002) A process risk model for the shelf life of Atlantic salmon fillets. Int J Food Microbiol 73: 47-60.

10. Gram L, Huss HH (1996) Microbial spoilage of fish and fish products. Int J Food Microbiol 33: 121-137.

11. Mulet M, Bennasar A, Lalucat J, Garcia-Valdes E (2009) An rpoD-based PCR procedure for the identification of Pseudomonas species and for their detection in environmental. Molecular and Cellular Probes 23: 140-147.

12. Fernández-No I, Guarddon M, Böhme K, Cepeda A, Calo-Mata P, et al. (2011) Detection and Quantification of Spoilage and Pathogenic Bacillus cereus, Bacillus subtilis and Bacillus licheniformis by real-time PCR. Food Microbiology 28: 605-610.

13. Viedma PM, Abriouel H, Omar NB, López RL, Gálvez A (2011) Inhibition of spoilage and toxigenic Bacillus species in dough from wheat flour by the cyclic peptide enterocin AS-48. Food Control 22: 756-761.

14. Ktari S, Mnif B, Koubaa M, Mahjoubi F, Ben Jemaa M, et al. (2012) Nosocomial outbreak of Myroides odoratimimus urinary tract infection in a Tunisian hospital. J Hosp Infect 80: 77-81.

15. Jooste PJ, Hugo CJ (1999) The taxonomy, ecology and cultivation of bacteria genera belonging to the family Flavobacteriaceae. Int J Food Microbiol 53: 81-94.

16. Nawaz M, Khan SA, Khan AA, Sung K, Tran Q, et al. (2010) Detection and characterization of virulence genes and integrons in Aeromonas veronii isolated from catfish. Food Microbiology 27: 327-331.

17. Daskalov H (2006) The Importance of Aeromonas hydrophila in Food Safety. Food Control 17: 474-483.

18. Friedemann M (2007) Enterobacter sakazakii in food and beverages (other than infant formula and milk powder). International Journal of Food Microbiology 116: $1-10$ 